\title{
Cholecystokinin-induced Excitation in the Substantia Nigra: Evidence for Peripheral and Central Components
}

\author{
D. W. HOMMER, M. PALKOVITS, ${ }^{* 1}$ J. N. CRAWLEY, S. M. PAUL, AND L. R. SKIRBOLL \\ Section on Molecular Pharmacology, Electrophysiology Unit, Behavioral Unit, Clinical Neuroscience Branch and * Laboratory of Cell \\ Biology, National Institute of Mental Health, Bethesda, Maryland 20205
}

\begin{abstract}
Cholecystokinin (CCK), one of the most common brain peptides, coexists with dopamine (DA) in neurons of the medial substantia nigra (SN). CCK has been shown to excite these neurons following either direct iontophoretic or systemic administration suggesting that peripherally administered CCK may cross the blood brain barrier to act directly on nigral DA cells. However, biochemical evidence suggests that CCK does not cross the blood brain barrier, and several studies have shown that the behavioral and the satietyinducing effects of peripherally administered CCK are abolished by vagotomy. In order to test for vagal mediation of the nigral response to systemically administered CCK, we examined the effects of a series of lesions to the vagal pathways on CCK-induced excitation in the SN. Neither acute thoracic nor chronic subdiaphragmatic vagotomies had any effect on the excitatory response of nigral DA neurons to systemically administered CCK. High cervical spinal cord transections were similarly without effect. In contrast, lesions of either vagal fibers in the medulla or of the efferent pathways from the nucleus tractus solitarii, the primary sensory nucleus of the vagus, produced significant attenuations of the nigral effects of systemically administered CCK. However, neither lesion blocked effects of CCK completely. We suggest that peripherally administered CCK has two components to its excitatory action in the $\mathrm{SN}$; a component probably mediated through CCK receptors in the nucleus tractus solitarii and a direct action on DA neurons.
\end{abstract}

Since its discovery in brain, cholecystokinin (CCK) has been studied extensively regarding its role as a neurotransmitter or neuromodulator (for a review, see Morley, 1982). CCK has been shown to have a number of metabolic and behavioral actions when administered either parenterally or intraventricularly. Among the effects reported following administration of CCK to animals are the development of hyperglycemia (Levine and Morley, 1981), hypothermia (Morley et al., 1981), analgesia (Zetler, 1980; Jurna and Zetler, 1981), satiety (Antin et al., 1975; Gibbs et al., 1973, Falasco, 1979), generalized central nervous system (CNS) depression (Zetler, 1981), and reductions in exploratory behavior (Crawley et al., 1981a). CCK has also been shown to have an excitatory action on neuronal firing rate following both parenteral and iontophoretic administration (Dodd

Received March 16, 1984; Revised October 1984;

Accepted December 5, 1984

\footnotetext{
${ }^{1}$ To whom all correspondence should be directed, at Clinical Neuroscience Branch, National Institute of Mental Health, Building 10, Room 4N214, 9000 Rockville Pike, Bethesda, MD 20205.
}

and Kelly, 1981; Jeftinija et al., 1981; Skirboll et al., 1981). Studies on the effects of CCK on feeding and exploratory behavior have raised the question as to whether behavioral and neuronal excitatory effects of CCK are mediated through a peripheral or central site of action. In this regard, intraventricular administration of CCK has been shown to reduce food consumption in some species and not in others (Della-Fera and Baile, 1979; Grinker et al., 1978). Since the major neural connection relaying viseral sensory information from the periphery is the vagus nerve, subsequent studies have sought to examine the role of the vagus in mediating the actions of CCK. Most, but not all, studies have found vagotomy can block CCKinduced satiety (Morley et al., 1982; Smith et al., 1981; Anika et al., 1977). It has also been shown that vagotomy prevents CCK-induced reductions in exploratory behavior (Crawley et al., 1981b).

Nemeroff et al. (1978) have shown that CCK can effectively reduce tail pinch-induced eating in rats. This is particularly interesting, since tail pinch-induced eating has been associated with central dopaminergic activity (Antelman and SLechtmarn, 1975) and CCK and dopamine (DA) have been shown to coexist in many neurons in the substantia nigra (SN) and ventral tegmental area (Hokfelt et al., 1980a). In a previous study, we reported that the administration of CCK excites cells in the mesencephalon which contain both CCK and DA (Skirboll et al., 1981). The excitation begins $10 \mathrm{sec}$ after CCK administration and has a duration of 2 to $5 \mathrm{~min}$. Since many of the actions of CCK have been attributed to its effects on the peripheral nervous system [i.e., vagal afferents to the nucleus tractus solitarii (NTS) (Crawley and Schwaber, 1984; Crawley et al., 1984)], we sought to examine whether the excitatory effects of CCK on DA cells were peripheral or central in origin. In the present study, the effects of peripherally administered CCK were examined in animals subjected to various lesions of the primary and secondary neurons of the vagal pathway in order to alter visceral afferents which relay information to the brain.

\section{Materials and Methods}

Recording procedure. Male Sprague-Dawley rats weighing between 200 and $260 \mathrm{~g}$ were used throughout these experiments. Animals were anesthetized with chloral hydrate $(400 \mathrm{mg} / \mathrm{kg}$, i.p.) and maintained under anesthesia during the course of the experiment with additional intravenous chloral hydrate as needed. Rats were mounted in a stereotaxic apparatus, the scalp and periosteum were reflected, and a 3-mm burr hole was drilled over the medial SN zona compacta, a region of DA cells many of which also contain CCK (Hokfelt et al., 1980b). Cells in this region have been shown to increase their firing rate following systemic administration of CCK (Skirboll et al., 1981). Cells were recorded from a region defined in the atlas of Paxinos and Watson (1982) as 1.0 to $1.8 \mathrm{~mm}$ lateral to midline and 3.0 to $4.0 \mathrm{~mm}$ anterior to the interaural line. Single-barrel micropipets (WPI 1B150F) filled with a $2 \mathrm{M} \mathrm{NaCl}$ solution saturated with $2 \%$ pontamine sky blue dye and with an impedance of 4 to 8 megohms (measured at $60 \mathrm{~Hz}$ ) were lowered into the brain using a 


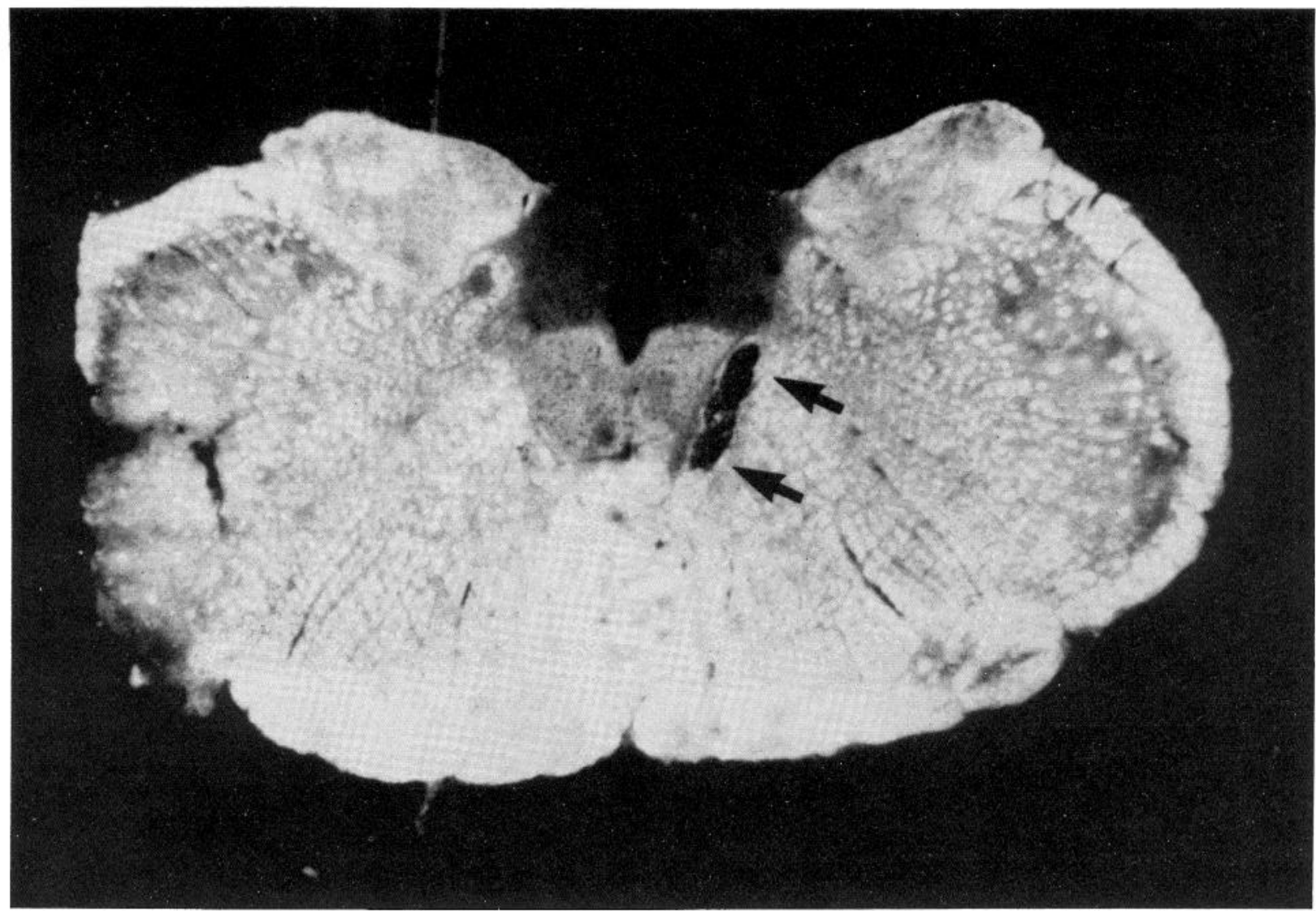

Figure 1. Coronal section through the caudal medulla showing the extent of a typical lesion of the vagal afferents to the NTS. Note course of the vagal fibers from the ventral surface of the medulla towards the lesion. Arrows designate the extent of the lesion.

Burleigh "Inchworm" microdrive (Burleigh Institute). Electrode potentials were passed through a high-impedance amplifier (WPI 750) and monitored on an oscilloscope (Tektronix F613) and audiomonitor (Grass AM8). The firing of single units was counted over 10-sec epochs using a window discriminator and rate meter (National Institute of Mental Health Instrumentation section) and the rates displayed on a chart recorder (Gould 2200 S) and a thermal printer (Datel CDPP.7). Core body temperature was monitored with a thermistor rectal probe and was maintained with a heating pad at 36 to $37^{\circ} \mathrm{C}$. Cells were identified as SN zona compacta dopamine neurons (ZC-DA) neurons on the basis of spike duration ( $>2 \mathrm{msec}$ ), shape (initial notched segment followed by a triphasic potential), and firing rate (<9 spikes/sec) (Bunney et al., 1973). Intracellular recordings from units with these characteristics combined with L-dOPA injections and subsequent histochemical examination have confirmed that they are DA-containing neurons (Grace and Bunney, 1980).

Lesions. Bilateral subdiaphragmatic vagotomies were performed under halothane anesthesia. The vagal branches were dissected free from the esophagus and sectioned just below the esophagealgastric junction. The esophagus was then scraped to ensure that all vagal fiber had been lesioned. Sham lesions were performed by opening the peritoneal cavity. The animals were allowed to recover for 8 to 10 days before recording.

Animals were prepared for acute vagotomy following chloral hydrate ( $400 \mathrm{mg} / \mathrm{kg}$, i.p.) anesthesia and tracheotomy. The rats were placed on a rodent respirator (Harvard Apparatus 680) and respired with room air at a rate and volume so as to maintain expired $\mathrm{CO}_{2}$ at 3.5 to 4.0. Expired $\mathrm{CO}_{2}$ concentration was monitored with a dualbeam infrared gas analyzer for $\mathrm{CO}_{2}$ (Infrared Industries 703-123). Animals were mounted in a stereotaxic apparatus, and a thoracotomy was performed using a posterior approach. The distal third of the thoracic esophagus was exposed and dissected free from surrounding tissues. Sutures were placed around the esophagus so as to allow easy access to it during recording. Recording was begun as has been described. After a ZC-DA neuron was located and its activity recorded for at least $5 \mathrm{~min}$, sulfated CCK $(20 \mu \mathrm{g} / \mathrm{kg})$ was administered intravenously. After the firing rate had returned to preCCK baseline for at least $5 \mathrm{~min}$, the distal portion of the thoracic esophagus was exposed and completely cut with surgical scissors. The activity of the cell was monitored for an additional $5 \mathrm{~min}$, and then a second dose of CCK ( $20 \mu \mathrm{g} / \mathrm{kg}$, i.v.) was administered.

Acute cervical spinal cord (C1) transections were performed on rats using the same anesthetic and respiratory techniques as in the acute vagotomy experiments. After being placed in the stereotaxic apparatus in a skull-flat position, the occipital muscles were exposed and separated; the atlantoccipital membrane was transected, and a 1.5-mm glass knife was positioned just caudal to the cerebellum and passed ventrally through the extreme caudal medulla and upper cervical spinal cord. Two minutes after the lesion was completed, the respirator was turned off for $20 \mathrm{sec}$ to determine if there were any spontaneous respiratory movements indicating the transection had been incomplete. If spontaneous respiration was absent, the respirator was restarted and recording begun. At the end of each experiment, the brain and spinal cord were removed and examined to determine if the spinal cord had been completely transected.

Unilateral or bilateral lesions of the medulla were performed under halothane anesthesia 8 to $10 \mathrm{~d}$ prior to recording. Rats were placed in a stereotaxic apparatus, and their heads were fixed in a maximal "nosedown" position. After separation of the occipital muscles, the atlantoccipital membrane was exposed and transected. Both types of lesions were made using a stereomicroscope. Unilateral lesions of the vagal afferents to the NTS and efferents from that nucleus were made with a $1.0-\mathrm{mm}$-wide glass knife positioned at the caudal border of the cerebellum and $2.0 \mathrm{~mm}$ lateral to the midline on the right side. The knife was oriented sagittally and aimed slightly rostrally 


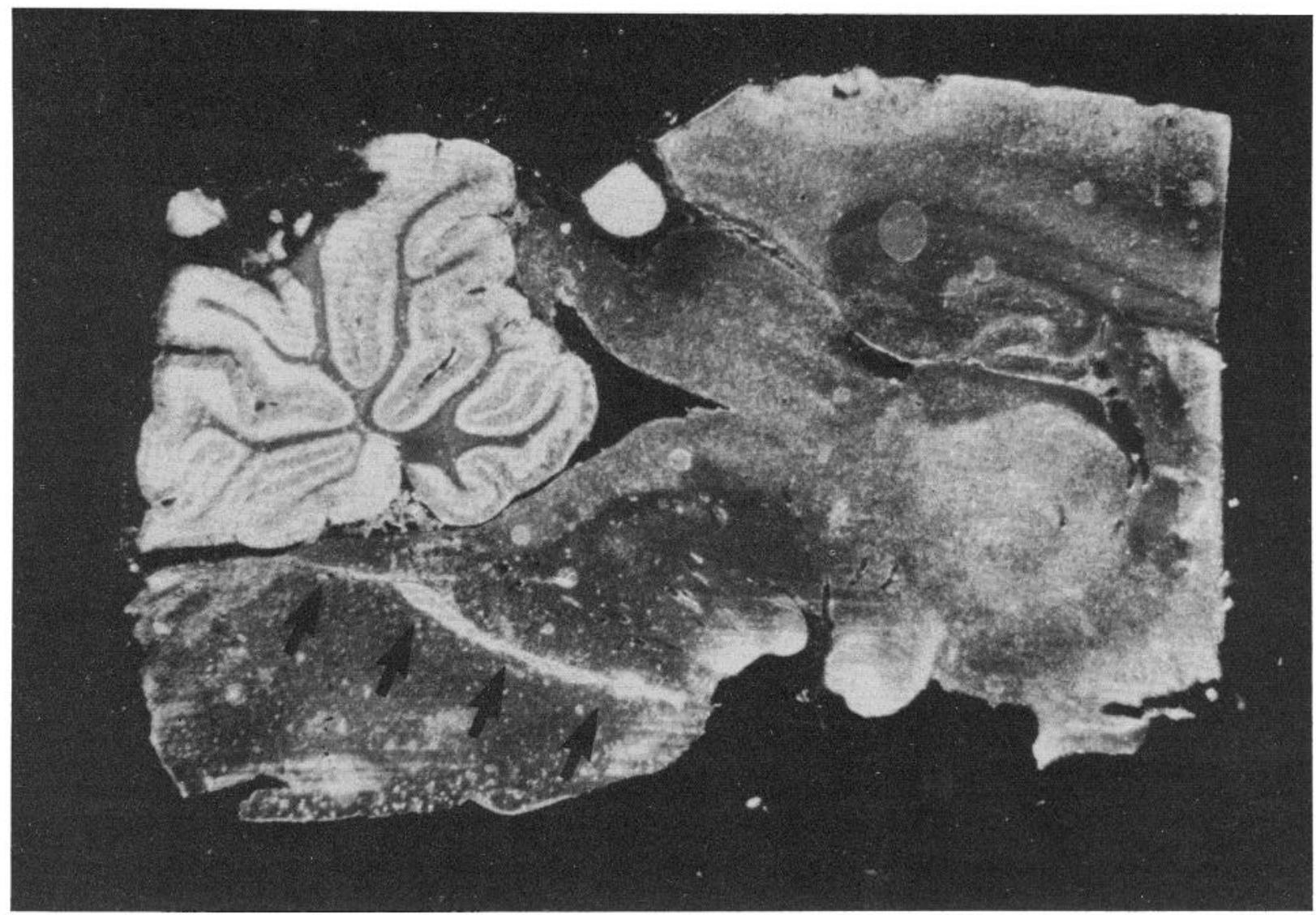

Figure 2. Parasagittal section through the brain stem. Arrows show the extent of a lesion of the efferent fibers of the NTS. These lesions were bilateral and were performed 8 to $10 \mathrm{~d}$ prior to recording.

at an angle toward the midline so that the lesion transected the solitary tract and other vagal fibers entering the medulla before they reached the NTS (Fig. 1). These lesions interrupt the NTS efferents, and also produced some damage to the lateral NTS, the spinal root of the fifth nerve, and the parvocellular reticular nucleus.

Bilateral lesions of the ascending efferents from the NTS were performed by placing a $1-\mathrm{mm}$ glass knife at the caudal edge of the cerebellum and aiming it rostrally on the coronal plane. The lesions were 2.5 to $3.5 \mathrm{~mm}$ deep (Fig. 2) and transected the rostral NTS bilaterally as well as the ascending ventral noradrenergic bundle. The prepositus hypoglossal nucleus, the medial vestibular nucleus, and reticular formation were also partially damaged. The vagal afferents to the NTS, however, remained intact in these animals. In order to control for the possibility of nonspecific effects of an intramedullary lesion which did not sever the ascending efferents from the NTS, a lesion was produced in an identical manner to the lesion which severed NTS efferents, except that in producing this control lesion, the knife was oriented in the sagittal plane rather than the coronal plane. Thus, these lesions were restricted to midline structures and did not involve the NTS or its efferents. For a summary of the lesions employed in these experiments, see Figure 3.

CCK administration and evaluation of response. All drugs were administered intravenously via the lateral tail vein. The CCK used in this study was sulfated CCK-7. It was the generous gift of Dr. V. Mutt (Karolinska Institute, Stockholm, Sweden). A standard dose of CCK $(20 \mu \mathrm{g} / \mathrm{kg})$ was used. The response to CCK was calculated as the percentage increase from base line activity. Base line firing rate was averaged over the 30 -sec interval immediately preceding CCK administration. The response of the cell to CCK was calculated during the $30-\mathrm{sec}$ interval beginning $20 \mathrm{sec}$ after completion of the CCK injection. This interval was chosen because it represented the period of maximum increase in rate induced by CCK (Skirboll et al., 1981).

One cell per animal was examined in all lesion groups except the unilateral NTS lesion group. In five of these animals, a ZC-DA cell from each side of the brain was studied. The side recorded from initially was randomly alternated so that in half of these rats CCK was administered first while recording from the lesioned side, and in the other half while recording from the unlesioned side. In another eight animals with unilateral NTS lesions, the response of the DA cell to CCK was examined only on one side (four ipsilateral and four contralateral to the lesion). At the end of each experiment, the cells were examined for the ability of apomorphine $(0.1 \mathrm{mg} / \mathrm{kg})$, a DA agonist, to inhibit firing rate and for haloperidol $(0.2 \mathrm{mg} / \mathrm{kg})$, a DA antagonist, to reverse this inhibition. All cells studied except half of those in the unilateral NTS afferent lesion group were inhibited by apomorphine, and this was reversed by haloperidol. The ZC-DA neurons on the side of the brain studied first in animals of the unilateral NTS lesion group were not tested with apomorphine and haloperidol, since these dopaminergic agents could influence the subsequent response to CCK on the contralateral side.

Histology. At the conclusion of each experiment, each animal was given a lethal dose of chloral hydrate, and the brain was removed and stored in $10 \%$ formalin solution. Brains were cut in 30 $\mu \mathrm{m}$ sections on a cryostat and examined under a dissecting microscope. Dye spots indicating recording site were found within the medial SN zona compacta in all cases. The location and extent of the lesions were also confirmed histologically, and data were used only from those animals whose lesions completely transsected NTS afferent and/or efferent fibers (Figs. 2 and 3). Animals with chronic vagotomies were also examined to confirm that no vagal fibers were present on the esophagus at the esophogeal-gastric junction. 


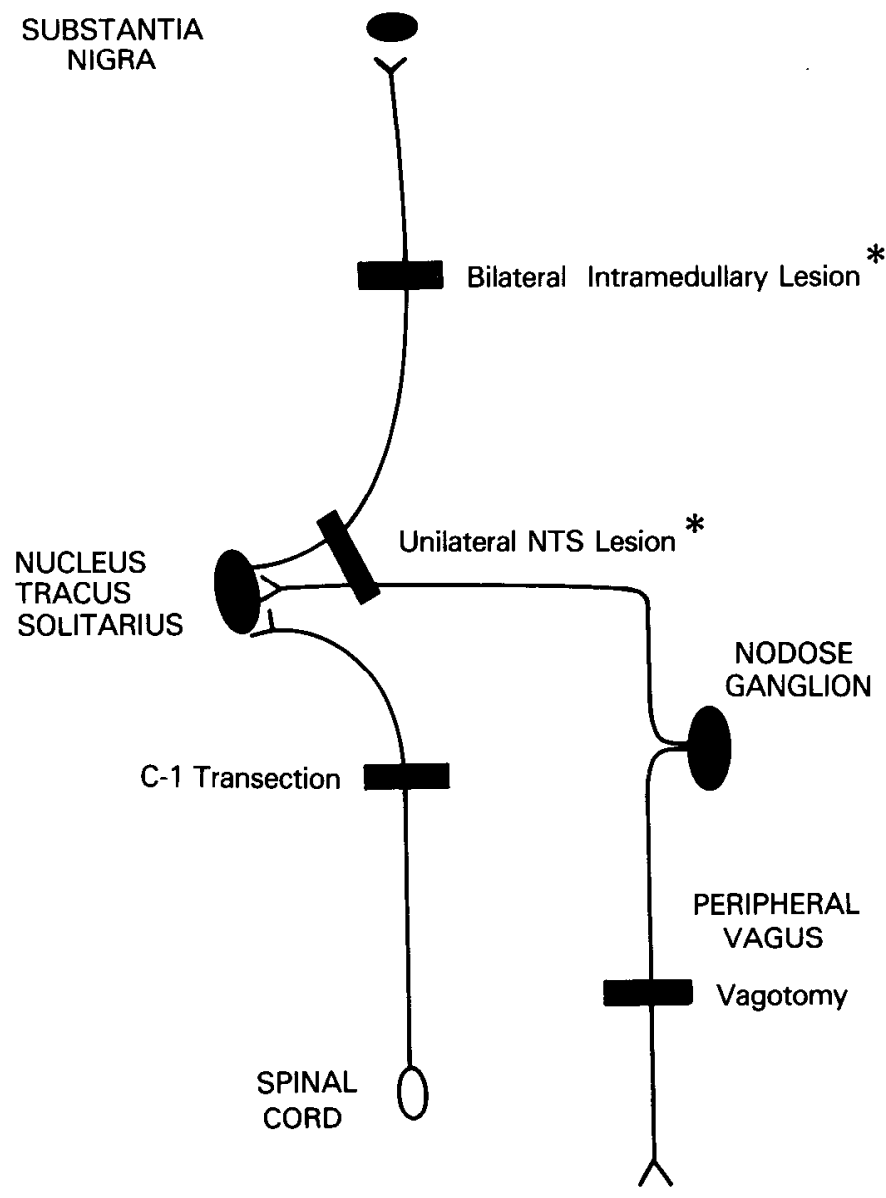

Figure 3. Schematic diagram of the location of the lesions employed in this study. *, lesions which produced a significant attenuation of the CCK effect on nigral DA neuron activity.

\section{CHRONIC VAGOTOMY}

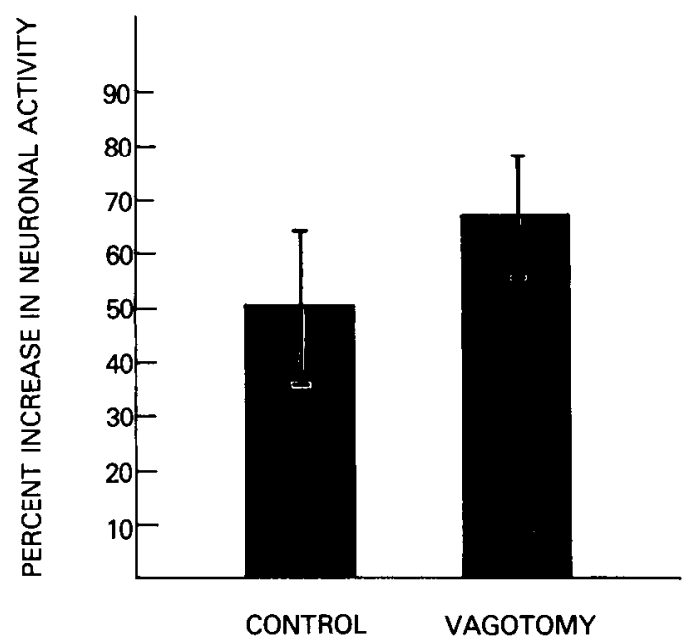

Figure 4. Subdiaphragmatic vagotomy did not attenuate the ability of systemically administered CCK $(20 \mu \mathrm{g} / \mathrm{kg})$ to increase the activity of DA containing neurons in the medial SN. The vagotomy and sham vagotomy were performed 8 to $10 \mathrm{~d}$ prior to recording ( $n=5$, for both groups).

\section{Results}

Bilateral subdiaphragmatic vagotomies performed 8 to 10 days prior to recording had no effect on the response of ZC-DA neurons to systemically administered CCK. Following administration of 20 $\mu \mathrm{g} / \mathrm{kg}$ CCK intravenously the firing rate of ZC-DA cells in vagoto-

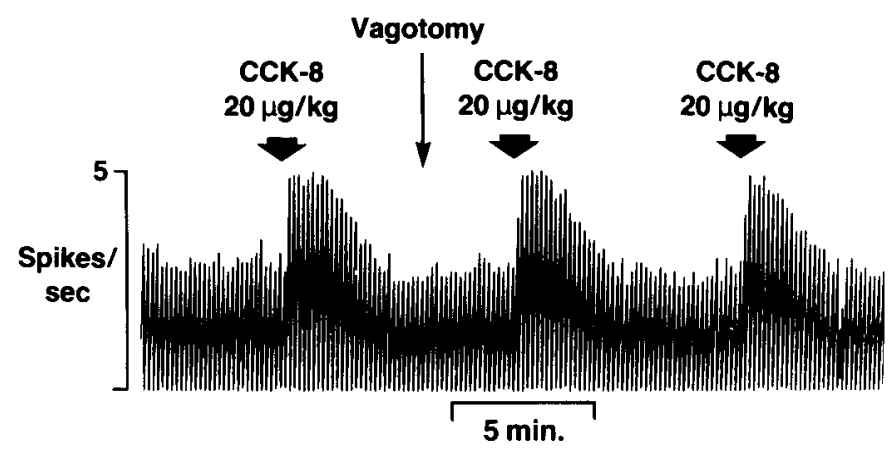

Figure 5. Intravenously administered CCK transiently increased the activity of this nigral DA cell. A vagotomy performed by transecting the thoracic esophagus while recording from this neuron did not alter the CCK-induced excitation.

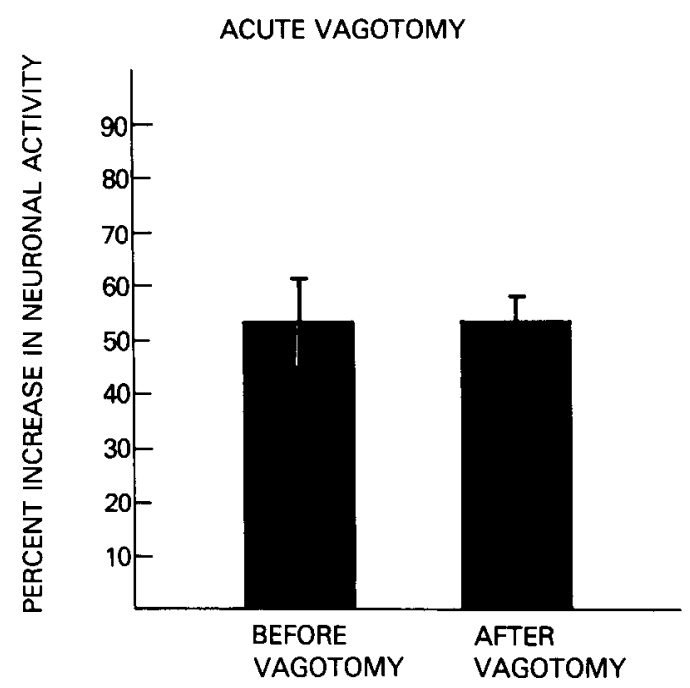

Figure 6. Acute vagotomy had no effect on the response of nigral DA neurons to systemically administered CCK $(n=7)$.

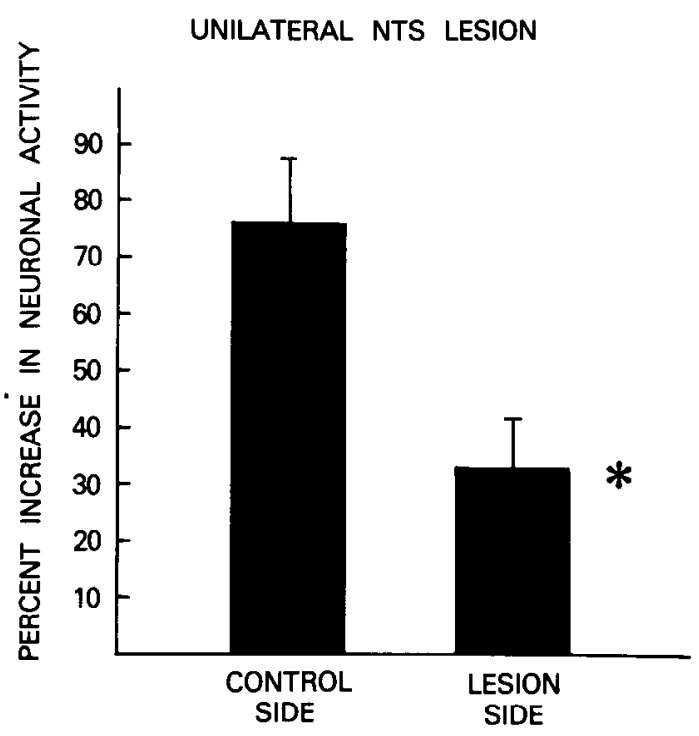

Figure 7. Unlateral lesion of the vagal afferent of the NTS in the medulla (Fig. 1) produced a significant attenuation of the effect of CCK on nigral DA neurons $(*, t=2.81, p<0.05, t$ test for independent groups; $n=9)$. 


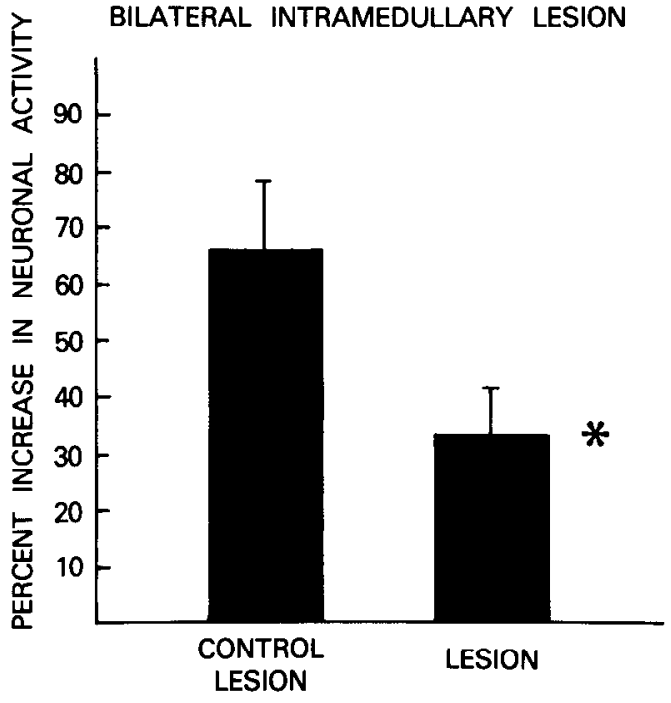

Figure 8. Lesions through the dorsal medulla of the efferents from the NTS (Fig. 2) produced a significant decrease in the response of DA neurons to peripherally administered CCK $(*, t=2.22, p<0.05, t$ test for independent groups; $n=6$ )

mized animals increased to $67 \pm 11 \%$ above predrug base line $(n$ $=5$ ); in sham-operated rats, the CCK-induced increase was $50 \pm$ $14 \%(n=5)$ (t test for independent groups: $t=1.01$; $d=8 ; p>$ 0.30 ; not significant) (Fig. 4). Similarly, an acute vagotomy (performed while recording the activity of ZC-DA neurons) had no effect on the ability of CCK to increase firing rate. Before vagotomy, CCK increased the activity of these neurons by $53 \pm 8 \%$. Then while continuing to record from the same neuron, a supradiaphragmatic vagotomy was performed by completely sectioning the esophagus in the thorax. Following this, CCK administration resulted in the same increase in activity as before vagotomy, i.e., $53 \pm 5 \%(n=7)$ (paired $l$ lesl; $l=-0.33, d l=6 ; p>0.40$; not significant) (Figs. 5 and 6 ).

A high cervical spinal cord transection performed immediately prior to beginning recording had no effect on CCK excitatory effects on ZC-DA cells. Following C-1 transection, ZC-DA neurons increased their firing rate $79 \pm 22 \%$ in response to $20 \mu \mathrm{g} / \mathrm{kg}$ systemically administered CCK.

In contrast to the failure of vagotomy and spinal cord transection to decrease the excitatory effects of CCK on ZC-DA cell activity, intracranial lesions of the afferent or efferent fibers of the NTS significantly reduced the excitatory action of CCK in the substantia nigra. A unilateral intramedullary lesion of both afferents and efferents of the NTS resulted in a significant decrease in the excitatory effect of CCK on ZC-DA neurons ipsilateral to the lesion as compared to ZC-DA neurons contralateral to the lesion. Cells on the same side as the lesions increased their activity by $34 \pm 9 \%$ following CCK, whilc cells on the oppositc side increascd their activity by $76 \pm 12 \%$ $(n=9)$ after CCK ( $t$ test for independent groups: $0.05, t=-2.81$; $d f=16 ; p<0.05)$ (Fig. 7)

Bilateral intramedullar lesions of the efferents from the NTS also produced a significant reduction of the ability of CCK to affect nigral DA neurons. CCK administration produced a $34 \pm 8 \%$ increase in ZC-DA cell activity in lesioned rats $(n=6)$ while increasing the firing rate by $66 \pm 12 \%$ in sham-lesioned control animals $(n=6$; $t$ test for independent groups: $t=2.22, d f=10 ; p<0.05$ ) (Fig. 8).

\section{Discussion}

We have previously shown that the i.v. administration of CCK elicits an excitatory action on cells in the SN which contain both $\mathrm{CCK}$ and DA. Since the sensory component of the vagus relays CCK-related information from the periphery to the CNS, we asked whether a component of the CCK-induced nigral excitation was mediated through this pathway. To examine this point, a series of lesions was performed on the vagal afferents and efferents to the nucleus tractus solitarii.

In the first series of experiments, acute supradiaphragmatic and chronic subdiaphragmatic lesions of the vagus were performed. We found that neither of these lesions was effective in altering CCKelicited excitation in the SN. In contrast, CCK-induced satiety and CCK-induced reduction in exploratory behavior have both reported to be abolished by vagotomy (Smith et al., 1981; Morley et al., 1982; Crawley et al., 1981b). Thus, our data suggest that the actions of CCK in SN are not involved in mediating either satiety or exploratory behavior.

The central terminal sensory relay nuclei of the vagus is the NTS. (For details, see Fig. 3). This nucleus has subdivisions which serve as relay centers for peripheral fibers traveling in the vagal nerves. Bipolar cells in the nodose ganglion send vagal projections to the gut and unilaterally to terminal regions in the NTS (Leslie et al., 1982). CCK immunoreactive tibers have been found in the NTS- and CCK-containing axons, and CCK receptors have been demonstrated along the vagus (Rehfeld and Lundberg, 1983; Uvnas-Wallensten et al., 1977; Zarbin et al., 1981). Palkovits et al. (1982) have shown that there are significant amounts of CCK in the NTS and that the peptide is extrinsic and vagal in origin. Thus, we sought to lesion afferents and efferents to and/or from this nucleus in an effort to determine if some site proximal or distal to the NTS might serve as a site of the peripherally administered effects of CCK on DA cells. In our studies, lesions of NTS afferents and efferents (unilateral lesion) or only efferents from the NTS (bilateral medullary lesion) significantly reduced, but did not completely abolish, CCK-induced excitation. Taken together with the inability of acute or chronic peripheral vagotomy to alter this response, our results suggest that the action of CCK is not dependent on the primary vagal neurons. Since our data show that peripheral vagotomy has no effect, while transection of NTS efferents attenuates CCK-induced excitation in the SN, it is possible that peripherally administered CCK acts directly on neurons in the NTS. Lesions in the medulla which severed fibers of the NTS to more rostral brain structures produced an attenuation comparable to unilateral lesion which transects both afferent and efferent fibers of the NTS, suggesting that it is the efferent fibers from the NTS to the SN which are involved in the action of peripherally administered CCK on DA neurons.

The extent of penetration of peptides through the blood brain barrier remains a crucial question regarding the peripheral versus central action(s) of exogenously administered brain peptides. In a single study of peripherally administered $\left[{ }^{125} \mid\right] C C K$, it was shown that i.v. administered CCK does not cross the blood-brain barrier (BBB) to an appreciable extent (Passaro et al., 1982). These data would suggest that any peripherally administered CCK must mediate its action through some peripheral site which subsequently relays its information to the brain. Our data would seem to rule out the vagus as being completely responsible for relaying the peripheral action of CCK on neuronal excitability. We have shown in previous studies that, iontophoretically administered, CCK is capable of eliciting an increase in dopaminergic neuronal activity which is comparable to the increase seen following peripheral administration. These data, coupled with the present findings that lesions of the NTS were effective in attenuating but not abolishing CCK-induced excitation suggest that, in addition to an action in the NTS, there may also be a direct effect of CCK on nigral neurons. It is also possible that CCK could act at some other brain site or through a nonvagal, nonspinally mediated peripheral site (e.g., cranial nerves). The discrepancy between BBB penetration studies and our data may be explaincd if the assay used were not sensitive enough to detect small but effective concentratins of peptide in the brain. Kastin et al. (1980) have presented evidence that small amounts of peptides may cross the BBB.

In summary, we suggest that the excitatory action of CCK on cells in the SN which contain both CCK and DA has two components: (1) a direct action on the nigral cells; and (2) an action probably in 
the brain mediated through fibers from the nucleus of the solitary tract in the medulla oblongata.

\section{References}

Anika, S. M., T. R. Houpt, and K. A. Houpt (1977) Satiety elicited by cholecystokinin in intact and vagotomized rats. Physiol. Behav. 19: 761766

Antin, J., J. Gibbs, J. Holt, R. C. Young, and G. P. Smith (1975) Cholecystokinin elicits the complete behavioral sequence of satiety in rats. J Comp. Physiol. Psychol. 89: 784-790.

Bunney, B. S., J. R. Walters, R. H. Roth, and G. K. Aghajanian (1973) Dopaminergic neurons: Effects of antipsychotic drugs and amphetamine on single cell activity. J. Pharmacol. Exp. Ther. 185: 560-571.

Crawley, J.N., and J. S. Schwaber (1984) Abolition of the behavioral effects of cholecystokinin following bilateral radiofrequency lesions of the parvoceltular subdivision of the nucleus tractus solitarius. Brain Res. 295: 289299

Crawley, J. N., S. E. Hays, S. M. Paul, and F. K. Goodwin (1981a) Cholecystokinin reduces exploratory behavior in mice. Physiol. Behav. 27: 407411

Crawley, J. N., S. E. Hays, and S. M. Paul (1981b) Vagotomy abolishes the inhibitory effects of cholecystokinin on rat exploratory behaviors. Eur. J. Pharmacol. 73: 379-380.

Crawley, J. N. J. Z. Kiss, and E. Mezey (1984) Bilateral midbrain transections block the behavioral effects of cholecystokinin on feeding and exploration in rats. Brain Res, 322: 316-321.

Della-Fera, M. A., and C. A. Baile (1979) Cholecystokinin octapeptides: Continuous picomole injections into the cerebral ventricles of sheep suppress feeding. Science 206: 471-473.

Dodd, J., and J. S. Kelly (1981) The actions of cholecystokinin and related peptides on pyramidal neurons of the mammalian hippocampus. Brain Res. 205: 337-350.

Falasco, J. D., G. P. Smith, and J. Gibbs (1979) Cholecystokinin suppresses sham feeding in the rhesus monkey. Physiol. Behav. 23: 887-890.

Gibbs, J., R. C. Young, and G. P. Smith (1973) Cholecystokinin decreases food intake in rats. J. Comp. Physiol. Psychol. 84: 488-495

Grace, A. A., and B. S. Bunney (1980) Nigral dopamine neurons: intracellular recording and identification with L-Dopa injection and histofluorence. Science 210: 654-656.

Grinker, J. A., B. S. Schneider, G. Ball, A. Cohen, A. Strohmayer, and J Hirsh (1978) Cholecystokinin (CCK-8) and bombesin (BBS) intracranial injections and satiety in rats. Fed. Proc. 39: 501

Hays, S. E., M. C. Beinfeld, R. T. Jensen, F. K. Goodwin, and S. M. Paul (1980) Demonstration of a putative receptor site for cholecystokinin in rat brain. Neuropeptides 1: 53-62.

Hukfell, T., J. F. Rehıleld, L. Skirboll, B. Ivemark, M. Goidstein, and K. Markey (1980a) Evidence for coexistence of dopamine and CCK in meso-limbic neurones. Nature 285: 476-478.

Hoktelt, T., L. Skirboll, J. F. Rehteld, M. Goldsten, K. Markey, and O. Dann (1980b) A subpopulation of mesencephalic dopamine neurons projecting to limbic areas contains a cholecystokinin-like peptide: Evidence from immunohistochemistry combined with retrograde tracing. Neuroscience 5. 2093-2124.
Jeftinija, S., V. Miletic, and M. Randic (1981) CCK8 excites dorsal horn neurons both in vivo and in vitro. Brain Res. 213: 231-236.

Jurna, T., and G. Zetler (1981) Antinociceptive effect of centrally administered caerulein and cholecystokinin octapeptide (CCK8). Eur. J. Pharmacol. 73. 326-331.

Kastin, A. J., C. Nissen, A. V. Schally, and D. H. Coy (1980) Additional evidence that small amounts of a peptide can cross the blood brain barrier. Pharmacol. Biochem. Behav. 11: 717-719.

Leslie, R. A., D. G. Gwyn, and D. A. Hopkins (1982) The central distribution of the cervical vagus nerve and gastric efferent and afferent projections in the rat. Brain Res. Bull. 8: 37-43

Levine, A. S., and J. E. Morley (1981) Cholecystokinin-octapeptide sup presses stress-induced eating by inducing hyperglycemia. Regul. Pept. 2: 353-357.

Morley, J. E. (1982) The ascent of cholecystokinin (CCK)-from gut to brain. Life Sci. 30: 479-493.

Morley, J. E., A. S. Levine, and S. Lindblad (1981) Intraventricular cholecys tokinin-octapeptide produces hypothermia in rats. Eur. J. Pharmacol. 74 249-251.

Morley, J. E., A. S. Levine, J. Kneip, and M. Grace (1982) The effect of vagotomy on the satiety effects of neuropeptides and naloxone. Life Sci. 30: $1943-1947$.

Nemeroff, C. B., A. J. Osbahr, G. J. Bissette, M. A. Lipton, and A. J. Prange (1978) Cholerystokinin inhibits tail pinch-induced eating in rats. Science 200: 793-794

Palkovits, M. J. Z. Kiss, M. C. Beinfeld, and T. H. Williams (1982) Cholecystokinin in the nucleus of the solitary tract of the rat: Evidence for its vagal origin. Brain Res. 252: 386-390.

Passaro, E., H. Bebas, W. Oldendorf, and T. Yamada (1982) Rapid appearance of intraventricularly administered neuropeptides in the peripheral circulation. Brain Res. 241: 335-340.

Paxinos, G. and C. Watson (1982) The Rat Brain in Stereotaxic Coordinates, Academic Press, Sydney.

Rehfeld, J. F. and J. M. Lundberg (1983) Cholecystokinin in feline vagal and sciatic nerves: Concentration, molecular form and transport velocity. Brain Res. 275: 341-347.

Skirboll, L. R., A. A. Grace, D. W. Hommer, J. Rehfeld, M. Goldstein, T Hokfet, and B. S. Bunney (1981) Peptide monoamine coexistence: Studies of the actions of cholecystokinin-like peptides on the electrical activity of midbrain dopamine neurons. Neuroscience 6: 2111-2124.

Smith, G. P., C. Jerome, B. J. Cushin, R. Eterno, and K. J. Simansky (1981) Abdominal vagotomy blocks the satiety effect of cholecystokinin in the rat. Science 213: 1036-1037.

Uvnas-Wallensten, K., J. F. Rehfeld, L. Larsson, and B. Uvnas (1977) Heptodecapeptide gastrin in the vagal nerve. Proc. Nat1. Acad. Sci. USA 74: $5707-5710$.

Zarbin, M. A., J. K. Wamsley, R. B. Innis, and M. J. Kunar (1981) Cholecystokinin receptors: Presence and axonal flow in the rat vagus nerve. Life Sci. 29: 697-705.

Zetler, G. (1980) Analgesia and ptosis caused by caerulein and cholecystokinin octapeptide (CCK-8). Neuropharmacology 19: 415-422.

Zetler, G. (1981) Central depressant effects of caerulein and cholecystokinin octapeptide (CCK8) differ from those of diazepam and haloperidol. Neuropharmacology 20: 277-283. 